\title{
On the Role of Dynamic Assessment on Promotion of Writing Linguistic Accuracy among EFL Learners: An Interventionist Model
}

\section{Sajjad Khorami Fard ${ }^{1 *} \&$ Zivar Derakhshi ${ }^{2}$}

\footnotetext{
* Correspondence:

Sajadkhorami66@gmail.com

1. English Department, Yasouj Branch,

Islamic Azad University, Yasouj, Iran

2. English Department, Marvdasht

(Shiraz) Branch, Islamic Azad

University, Marvdasht, Iran
}

Received: 1 February 2019

Revision: 31 March 2019

Accepted: 8 April 2019

Published online: 20 June 2019

\begin{abstract}
This study is conducted under the domain of Vygotskian Socio-cultural Theory (SCT) of mind and the notion of dynamic assessment to elevate the linguistic accuracy of EFL learners' writing skill. 40 homogenous intermediate English as a foreign language (EFL) learners from four intact classes were divided into two dynamic assessment (DA) and non-dynamic assessment (NDA) groups. As a pre-test, the participants were given writing topics during a course to assess their writing linguistic abilities. After analyzing and scoring the compositions' errors based on four consecutive stages to error analysis and a model of linguistic errors (grammatical, syntactic, substance, and lexical), the type and frequency of errors' subcategories related to each category $(n=516)$ was detected. Afterwards, the DA group went through intervention/mediation (interventionist dynamic assessment) based on their pre-test errors in five sessions, while nondynamic assessment group received no mediation and feedback. The pretest-mediation-post-test design (sandwich model of dynamic assessment) was used in this study. After mediation, as a post-test, both groups entered the second course of language learning and like pre-test their compositions during the course were analyzed and scored to see the effect of dynamic assessment on learners' writing ability. Analysis of data through descriptive statistics and statistical analysis showed that the experimental group who received mediations, unlike control group, solved their writing difficulties extensively and outperformed the control group with a significant difference. In other words, application of DA as an alternative procedure to standard testing has a positive effect on both test performance and writing linguistic accuracy of EFL learners.
\end{abstract}

Keywords: dynamic assessment, interventionist, sandwich format, zone of proximal development (ZPD), writing linguistic errors 


\section{Introduction}

Having a profound root in Vygotsky's perspective of cognitive development dynamic assessment (hereafter DA) grabbed the attention of many psychologists and educators all around the world. It is originated from Vygotsky's $(1986,1978)$ Socio-cultural Theory (SCT) of mind and the concept of Zone of Proximal Development (ZPD), which have appeared as an answer to needs to integrate socio-cultural factors in understanding of cognitive development and learning potential (Tzuriel, 2000). Vygotsky's SCT believes that learning is a social process that occurs within social interaction with others. Vygotsky (1986) defines ZPD as the gap between actual developmental level as determined by independent or by-own problem solving activity and the level of potential development as determined in the process of problem solving under the control or help of an adult or a peer or in pair with more capable people. Then what they do with collaboration can be done independently in the future and becomes his potential ability.

Successful outcomes of DA in psychological therapy in nurturing learning potentials were welcomed by different scholars in applied linguistics (Ableeva, 2010; Anton, 2009; Dunn \& Lantolf, 1998; Haywood \& Lidz, 2007; Poehner, 2005). Following the sociocultural theory in Vygotsky's notion these researchers believe that language acquisition and learning can be gained through interactions. Haywood and Lidz (2007) refer to DA as an integrative, testmediation-retest form of psychological and psycho-educational testing, which is a rapidly developing path of growing interest to practicing psychologists. Psycho-educational assessment refers to the psychological aspect of education in which instruction results in learning if psychological functions or developmental potentials of learners are well managed.

So in Vygotskian perspective toward DA, development is focused which is the activation of higher mental functioning levels of the learners. This psychological functioning level emerges through dynamic intervention of a more expert one. However, entering DA in educational settings needs from clinical settings was a novel reform in assessment approaches. The crucial element in educational settings would be all professionals who do assessments and are engaged in the education and diagnostic intervention of the learner (Haywood \& Lidz, 2007). If assessment is supposed to be effective enough to help learners learn appropriately, it must enter the teaching and learning processes rather than putting off to the end of instruction (Shapard, 2000).

DA among other types of assessment has this feature and instruction and assessment are not away from each other within it and the main concept of it. "This new method, DA, is a procedure for simultaneously assessing and promoting development that takes account of the individual's or group's with blending assessment and instruction so, the learners are to understand their abilities in the assessment procedure and promoting development during the assessment process itself (Poehner \& Lantolf, 2004).

\subsection{Statement of Problem}

Writing is the integral part of EFL learning and pedagogy. It is vital for learners to acquire enough competence and mastery in written English to complement learning and academic success. Looking back at the history of EFL research and the results of the studies conducted on writing accuracy one can discover a category of errors along with a comprehensive report of the sources of these errors. In spite of these viable findings, creating accurate sentences has been a huge concern among EFL learners. It can be as the result of ill management of the detected errors, adopting traditional approaches, product oriented methodologies or lack of special instruction and assessment in part of teachers in the classroom. These can be the most seen barriers to language acquisition specially writing accuracy promotion in which learners don't know how to internalize language knowledge to obtain mastery in the intended area. One approach to removing barriers in language learning with a sociocultural foundation is a process writing approach in which instruction and assessment is no longer separated but even integrated. In this approach, dynamic interventions in part of the tutor not only let the learners reach their current writing abilities but also obtain cognitive development and future potentials. So the result of interventions is a vital issue that DA takes into consideration. In EFL education, instruction and assessment must be integrated if the primary objective is the development of subjects. In spite of emergence of the DA in two decades and its contributions to language learning development in EFL and ESL settings, it is not a part of teaching program especially in EFL environments.

Entering DA approaches due to their reflective problem-solving, dialogic, process oriented and dynamic characteristics can meet the goals of teaching and assessment and bore learning and development, what that cannot gain through static, correction methodologies and task-giving behaviors. The major contribution of this DA-based study in EFL writing education is the combination of error analysis with dynamic approaches to remove the real time 
errors. Error analysis is a useful element in language learning and teaching through which many teaching shifts and learning behaviors have been done in educational settings. In spite of the privilege of error analysis in the analysis of errors, a new method is needed to be adopted to alleviate the errors in process with immediate actions. Although collecting a set of errors and their sources can be useful, it may not highlight the future and potential cognitive abilities of individuals. This assumption, therefore, welcomed by many researchers and teachers to shift toward a novel method of assessment on which they help individuals develop with the aid of mediations. Because of the failure of static assessment in fulfilling this development and efficacy of the DA principles in many studies (Ableeva 2008, 2010; Anton, 2009; Dunn \& Lantolf, 1998; Poehner, 2005; Shrestha, 2011; Xiaoxiao \& Yun , 2010 ) and also not many studies in EFL writing accuracy, entering this new model of assessment into classroom instruction with a proper intervention in part of the teacher, many problems of EFL writing would be healed and more information about the individual's learning ability would be obtained.

However, in line with the above mentioned researchers, the present study directed under the area of applied linguistics and has a relevance to foreign language acquisition and language teaching. It reveals the social element of language assessment established in Vygotsky's socio-cultural theories of mind and on top of that the idea of Zone of Proximal Development aiming at detecting writing linguistic errors among learners of English in an EFL setting and applying interventionist DA to promote EFL writing abilities.

\subsection{Research Questions}

To meet these goals, a number of research questions were designed. They are as follows:

1. What are the types and frequencies of linguistic errors which EFL learners commit in their writing performances?

2. To what extent can the interventionist model of dynamic assessment promote the EFL learners' writings and alleviate linguistic errors?

3. Is there any significant difference between the writing performances of dynamic and non-dynamic learners in promoting their linguistic problems?

\section{Literature Review}

\subsection{DA Models}

There are different models of DA introduced by interested researchers in the history of DA. These models separately adopt different procedures in providing mediation. On this basis, two primary approaches were introduced by Lantolf and Poehner (2004). These approaches to DA are interventionist and interactionist. According to Poehner (2005), these two approaches represent two general kinds of mediation that DA researchers can provide in practice and can include a variety of supports, from standard hints to verbal interaction. Interventionist DA employs standardized procedures and assistance forms in its administration to reach numerical results which are used as a means of comparison and contrast among groups and other measures to predict future performance on the tests (Poehner, 2005). Poehner and Lantolf (2005) placed interventionist DA in Vygotsky's quantitative interpretation of ZPD as a 'difference score.' Further, Interactionist DA, according to Lantolf and Poehner (2004), offers mediation and assistance, different from that of interventionist DA, in form of interaction between the examiner and the examinee and further is sensitive to the examinees' ZPDs. Minick (1987) stresses this matter and believes that interactionist procedures of DA, unlike the interventionist models, rooted in the Vygotsky's tendency toward qualitative assessment of psychological processes and dynamicity of their development (Poehner \& Lantolf, 2004).

\subsection{Related studies}

A number of studies have been conducted in the area of DA in recent years and more specifically the researches done on the instruction and assessment of the written language. DA applications have initiated in L2 research through the last two decades (Abdolrezapour, Tavakoli, \& Ketabi, 2014; Ableeva; 2008, 2010; Antón, 2009; Kozulin, \& Garb, 2002; Poehner \& Lantolf, 2013) and to date there have not been many researches on grammatical errors of writing skill, although a lot of studies conducted on writing were based on error analysis procedures (Napitupulu, 2017; Sermsook et al., 2017).

For example, Xiaoxiao and Yun (2010) conducted a case study of DA in EFL process writing. The result obtained from this study represents two major objectives; 1) Learners' writing ability can be substantially and comprehensively improved; 2) Learners' motivation of writing can be markedly stimulated. However they found DA as it can affect the 
whole process of writing. They also stressed the role of interaction between mediators and learners aided by language (dialogue) or other mediational tools (mediation). They reported that since the mediation is made in the ZPD of learners, remarkable progress is likely to occur.

In addition, Shrestha (2011) conducted a study on DA of academic writing for business studies. The study investigates whether, and if so, how DA enhances students' academic writing and conceptual development in business studies over time. It was reported that DA provides insights into the learners' maturing writing abilities, which the tutor can nurture further to help the learners internalize them. This study also shows that DA students made more gains than their nonDA counterparts regarding their ability to write a case study analysis genre. Additionally, the findings suggest that students can transfer their academic writing and conceptual knowledge from one assessment task to another, albeit at a varying level.

Isavi (2012) investigates effectiveness of DA on Iranian L2 writing performance using the regulatory scale offered by Aljaafreh and Lantolf (1994) to Iranian EFL learners' writing ability. The participants were a class of 15 preintermediate EFL learners, all males and ranging in age from 14-17, learning English at Iran Language Institute, Tehran, Iran. This study shows that almost all participants had difficulties in their writing ability and were only able to perform better with mediator guidance. He reported that a DA approach can successfully improve EFL learners' writing ability. The results also suggest that a DA approach to writing enables the teacher to more accurately evaluate learners' writing skill and after identifying the nature of the error provide the learners with necessary support and, therefore, improve their writing.

Applying DA in ESL writing classroom, Miao and Lv (2013) reported that teacher's guidance and intervention, peer cooperation, and students' active involvement in the process of progress can alleviate and remove the barriers to learning. They also reported that dynamic treated individuals benefitted from dynamic interventions and made much progression than non-dynamic group and ESL writing abilities can be grown under the cover of DA approaches. Alemi's (2015) study investigated general English students' evaluation of their writing ability before and after taking a DA-based writing course. The results suggested that DA could improve Iranian EFL learners writing abilities. The results also suggest that a DA approach to writing resulted in a proper teacher evaluation after identifying the nature of the error provide the learners with necessary support and, therefore, improve their writing. In this study, the dynamic group after mediation outperformed the non-dynamic group in post-test.

Taheri and Dastjerdi (2016) in their study investigated the impact of DA on EFL learners' picture-cued writing. They reported a DA approach can truly boost EFL learners' writing ability. They also reported DA approach to writing makes the teacher to more properly assess learners' writing skill and after detecting the source of their errors provide them with essential scaffolding and as a result boost their writing. Parsi and Sanavi (2015) probed writing proficiency of 45 Iranian intermediate EFL learners was investigated. The outcomes of this study showed that using DA instruments affects writing ability of Iranian female adult EFL learners and boost it greatly. It was also reported that DA in EFL classes can reveal the weaknesses of the learners and provide interventions when it is needed.

Too, the applicability of DA on other aspects of language learning has been proved in the literature. Among all, Poehner (2005) conducted a DA of oral proficiency among six advanced L2 learners of French. The results of the analysis were utilized to structure a six-week long DA program in which the subjects met with the mediators for individualized training. Based on the discoveries of the investigation, he detailed that DA is a viable methods for understanding students' capacities and helping them to conquer linguistic issues. Furthermore, Ableeva (2010) explored L2 listening comprehension on college level intermediate students of French and reported that DA can act as means of problem solving along with proper mediations where individuals need progress. It was found that through activating learners' ZPDs, actual level of them will be recognized as well as their potential levels of listening ability.

Another study done by Toe (2012) on five Taiwanese EFL learners' reading skills and had very fruitful outcomes. He reported that DA can promote reading skills and facilitate internalization of new knowledge of reading comprehension. Further, it was concluded that correct application of DA approaches helps the researcher make use of reflections and lesson plan reform to develop learners' knowledge. In a parallel result, after applying dynamic approaches on five second-year English majors from a technical college, Wang (2015) reported that interventionist DA is able to realize lower intermediate EFL learners' listening comprehension potentials and develop problem solving behaviors among these learners. It was also concluded that integrating assessment and listening instruction can implement DA requirements to promote mental and future development. 
In addition to the studies above, many others revealed the applicability of DA. Hidri (2014) carried out a study aims at addressing a need to examine and improve current assessments of listening of Tunisian university EFL test-takers. Her study revealed that DA provided better insights into learners' cognitive and meta-cognitive processes than did the traditional static assessment and reported that raters were doubtful about the value of DA because they did not know it well. Ajideh and Nourdad (2012) reported that DA can be useful for EFL readers and its effect remains over time. In addition, learners of low-, mid-, and high-proficiency levels improve their reading comprehension ability almost equally and the proficiency level doesn't affect the amount of taking the advantage of dynamic assessment.

\section{Methodology}

\subsection{Research Design}

This study accomplished a mixed method design utilizing both qualitative and quantitative approaches to do the experiments and describe its results. It used a content analysis method to find errors in the students' compositions. Further, to complement the requirements of DA, the pedagogical experiment design in the study aligned itself with the interventionist approach (Sandwich Format) by Sternberg and Grigorenko (2002) with a test-teach/interventionretest methodology to measure the effect of treatment. This DA model is in Vygotsky's quantitative interpretation of ZPD as a 'difference score' and employs mediations to reach numerical data. Generally, this study adopts a QuasiExperimental class: nonequivalent control (comparison) groups design to be conducted.

\subsection{Participants}

40 Persian speaking participants (20 male and 20 female) met the requirements of this research. They were students of English language, from 17-25 years of age, who regularly took English classes at courses titled "American English File 3" in Soroush Language Institute, Yasouj City, Iran. They are on the intermediate level of English proficiency and were chosen from four intact classes through a convenience sampling procedure due to the practical criteria of availability, easy accessibility (intact-classes design). Their levels of proficiency were intermediate which refers to the number of semesters they have spent studying English at the Language College but to make sure of their proficiencies they were homogenized at the beginning of the study with a placement test.

\subsection{Instruments}

To collect relevant data for the study, two instruments were employed purposefully: oxford quick placement test (OQPT) and a list of teacher-made writing tasks.

\subsubsection{Oxford Quick Placement Test (OQPT)}

For the participants to be homogenized in their general language proficiency, an OQPT was taken. The paper and pencil version of the test was administered to the students which contains two parts. Part one of this test containing 40 multiple choice questions was adopted by the researchers to be administered and based on the test's guidelines, those who scored between 24 and 30, were considered intermediate. It is quick, time saving, and validated in 20 countries by more than 6,000 students and was administered as a time-saving and reliable English language proficiency test developed by Cambridge ESOL and Oxford University Press.

\subsubsection{Teacher-made Writing Tasks}

As a pretest and post-test for the quantitative phase of the study, a set of 10 writing topics close to the learners' interests was employed by the researchers that each was done in the classroom as a piece of writing task during the course. These topics were scored one time at the end of the first semester of language class as the pre-test and one another time at the end of the second semester as the post-test of the study.

\subsection{Procedure}

At the first step of this research, a QOPT was administered in order to identify the homogeneity of the participants. 40 out of 45 participants in four intact classes were selected as the intermediate-level learners and the rest were eliminated. Then these students were divided into groups of control and experimental and equally assigned into one experimental (male $n=20$ ) and one control group (female $n=20$ ). Whole process took two semesters in two months. The first semester was considered as a sort of error analysis of the learners' compositions and scoring them individually. In this first semester, the researchers collect sufficient data through the weekly compositions of the students on the topics close to their interests that done in the classroom as a piece of writing task. Every week included 
two sessions in which the students were supposed to write about a topic each session. The topic of each piece of writing was close to the students' interests (their favorite sports, birthday planning, daily activities and etc.) to motivate them to write and express their thoughts. Ten pre-determined topics were chosen for this matter and each learner's composition was investigated during the course. Each composition was analyzed and the error types were recorded. After detecting all error types in students' ten scripts, each composition scored out of 13, then sum of all compositions' gained scores were the total score of each learner in the pre-test phase. The scoring process was based on the 13 linguistic errors detected from scripts. Each component missing in each paper was considered as 1 point/score subtraction from 13. It was to reach the actual knowledge of learners' linguistic competence and to know if this competency among learners is the same. In addition, the frequency number of each error in each learner's composition was recorded at the end of each paper for later presentation of count and frequency of errors in tables or graphs. This part of data collection was done based on the guidelines of Ellis's (1994) error analysis as following: a) Defining a corpus of language, b) Identifying errors, c) Classifying errors, and d) Explaining errors.

According the Ellis (1994), any error analysis requires these procedures. In addition, the identification and classification operation of errors was based on Hubbard's et al. (1996) model of linguistic errors classification namely grammatical, syntactic, substance, and lexical errors. The scoring process was based on an analytic scoring of compositions. Analytic scoring is a sort of rating scale where a candidate's performance (for example in writing) is analyzed in terms of different components (for example word order, syntax, and punctuation). So, the scoring was based on the 13 components of linguistics related to each part of the above model. All these steps were to know the type and areas of learners writing errors of structure. In addition, these steps pave the way for the teacher to benefit from these detected errors and apply proper mediation forms in his part for the learners to best suit their ZPD and help them alleviate their problems. So, based on the types of errors detected from learners' scripts, 5 mediation and scaffolding sessions at the end of the course/semester were allocated. All learners of experimental group were informed of the benefits of these sessions in removing their writing problems of sentence structure and increasing their accuracy and invited to these sessions. In these interventionist sessions, all help in part of the teacher was based on the learners' errors in the first semester's pre-tests. The experimental groups received mediation whereas the control groups experienced the traditional way of learning writing. Each of two most frequent error types was investigated each session with treatment group. In these sessions in line with Poehner's (2005) view, intervention is similarly sandwiched between a statically administered pre-test and posttest and performance on the post-test can then be compared to the pre-test in order to determine how much improvement an individual made as a result of the intervention. In this interventionist approach, the Sternberg and Grigorenko's (2002) 'Sandwich Format, the hints or prompts and recasts based on the needs of the students and the kind of the problem, were presented to the students in an implicit-to-explicit format as following:
1. Take a look at your writing to edit it
2. Focus on highlighted incorrect form
3. Think about the correct form
4. Ask other peers for assistance
5. The teacher gives an example
6. The teacher explains the rule

The individuals were given their compositions in which the errors were highlighted. Error scaffolding was started with the two most frequent ones by the learners. Scaffolding and intervention was done in a group format based on the prompts above. They start with the most implicit prompt to the most explicit one until they make the correct form and revise the faulty area. After each session of mediation, the students were given homework to practice what they had learned. The process went on until the fifth session and the two least frequent error types. In order to achieve the main goal of the research which was investigating the effect of treatment, both the experimental and control groups were asked to participate in a post-test. According to Poehner (2005), a post-test would determine the effectiveness of treatment sessions. However, the participants entered the second semester in which they were given the same topics as the same process in the first semester. The error analysis was done on each composition based on the determined error types to reach a score for each one. Then, as in the first semester, the sum of all compositions' scores was the total score of each student. Finally, they were compared with pre-test scores in order to assess the differences and signs of improvement. The number and type of errors in this part were not reported because the focus was on the effect of mediation to increase the score of students in post-test. If the scores increase after mediation, it can be said the error numbers decreased as the result of DA application. 


\subsection{Data Analysis}

To determine the types and numbers of the intermediate EFL learners' linguistic errors of writing, the guidelines of Ellis (1994) were adopted. In this model, detecting the errors and classifying them was accomplished according to Hubbard's et al. (1996) model of linguistic errors. Further, since the main objective of this study was to consider the effect of DA and more specifically interventionist approach, considering the significant differences between the groups is of a high significance. Moreover, the extent of mediation and scaffolding effects on the DA group during intervention sessions was measured running a Paired sample t-test. Then, to mark the signs of DA learners' cognitive development and outperformance in comparison with non-dynamic/traditional ones, another independent t-test was adopted. All analyses were done quantitatively using 19 version of Statistical Package for Social Sciences (SPSS) software.

\section{Results}

The principal statistical analyses conducted in this quantitative study was paired t-test and independent t-test to evaluate the effect of interventionist DA as the independent variable on the promotion of EFL learners' writing accuracy as dependent variable and also to mark the performance difference of the two DA and non-DA groups at the beginning and at end of the study. So, t-tests were chosen as the most appropriate analysis to compare performance on two groups (Mackay \& Gass, 2006) as the aim of the study was to examine the effect of one independent variable on another dependent variable. In addition, an analytic model in the name of Ellis (1985) which contains procedures to do error analysis of EFL learners' corpora of written language was adopted in which error analysis was done by detecting the errors and classifying them according to Hubbard's et al. (1996) model of linguistic errors classification namely grammatical, syntactic, substance, and lexical errors.

Grammatical errors: proposition, noun (plural and singular), verb, article and conjunction.

Syntactic errors: pronoun, word order, grammatical agreement (subject-verb agreement, adjective-adverb agreement and antecedent).

Substance errors: punctuation, spelling and capitalization.

Lexical errors: word choice

\subsection{Result of Error Analysis of the Learners' Writings}

The analysis of linguistic errors made by intermediate students in all of their compositions was examined and categorized in Table 1.

Table1. Analysis of error types of the intermediate students' compositions

\begin{tabular}{|c|c|c|c|}
\hline Error types & count & percentage & examples \\
\hline Capitalization & 100 & $19.37 \%$ & yasouj city, iran, i want to talk about america then I .......... \\
\hline Spelling & 89 & $17.24 \%$ & Brehte deeply, tak care, mange, aloun \\
\hline Preposition & 55 & $10.65 \%$ & $\begin{array}{l}\text { I live Yasouj, I get up on morning, to climb to the mountain, in } \\
\text { the Yasouj. I want go to Yasouj. }\end{array}$ \\
\hline Verb & 50 & $9.68 \%$ & $\begin{array}{l}\text { Everybody need money. we are must a good friend. My father's } \\
\text { name Ali. My mother ordered me and I write a letter. We can to } \\
\text { make friends. }\end{array}$ \\
\hline Punctuation & 46 & $9.91 \%$ & How are you. I get up at 6 I eat breakfast then I go out. \\
\hline $\begin{array}{l}\text { Grammatical } \\
\text { agreement-sub- } \\
\text { verb agreement } \\
\& \text { antecedent }\end{array}$ & 34 & $6.58 \%$ & $\begin{array}{l}\text { He say to me. He need money. He go out every night. My mom } \\
\text { does his work at home. I do my homework myselves. I made } \\
\text { friend with Sara. He was twenty. }\end{array}$ \\
\hline
\end{tabular}




\begin{tabular}{|c|c|c|c|}
\hline Article & 34 & $6.58 \%$ & The iran. I'm student. I go for walk. \\
\hline Noun & 27 & $5.23 \%$ & $\begin{array}{l}\text { I have two sister. After } 3 \text { day I called. My family are the best } \\
\text { thing. The iran country..... }\end{array}$ \\
\hline Conjunction & 27 & $5.23 \%$ & I cant play chess and I can play soccer instead. \\
\hline Pronoun & 23 & $4.45 \%$ & I talked to him brother. The first day went to the beach. \\
\hline $\begin{array}{l}\text { Adjective- } \\
\text { Adverb } \\
\text { agreement }\end{array}$ & 21 & $4.06 \%$ & $\begin{array}{l}\text { I went with some student. I like to speak English goodly. When } \\
\text { I listen to suddenly news. Many information }\end{array}$ \\
\hline Word order & 0 & $0 \%$ & - \\
\hline Word choice & 10 & $1.93 \%$ & $\begin{array}{l}\text { I passed concur exam two years ago. The whether was rainy. } \\
\text { Its very difficult ... }\end{array}$ \\
\hline
\end{tabular}

Table1 indicates the count and percentage of each error type in a hierarchy of descending order. It also represents the qualitative analysis of errors in students' writings. Of these, 516 errors shown in Table 4.1, 100 errors were related with capitalization and 89 errors were also related with spelling and 55 errors were linked to preposition. Errors related with verbs were 50 and punctuation errors were 46. Grammatical agreement and article errors were each 34 . Errors regarding nouns and conjunction were each 27 , pronoun errors were 23 , and 21 errors were in part of modifier. The least error types were word choice with 10 and word order with no error.

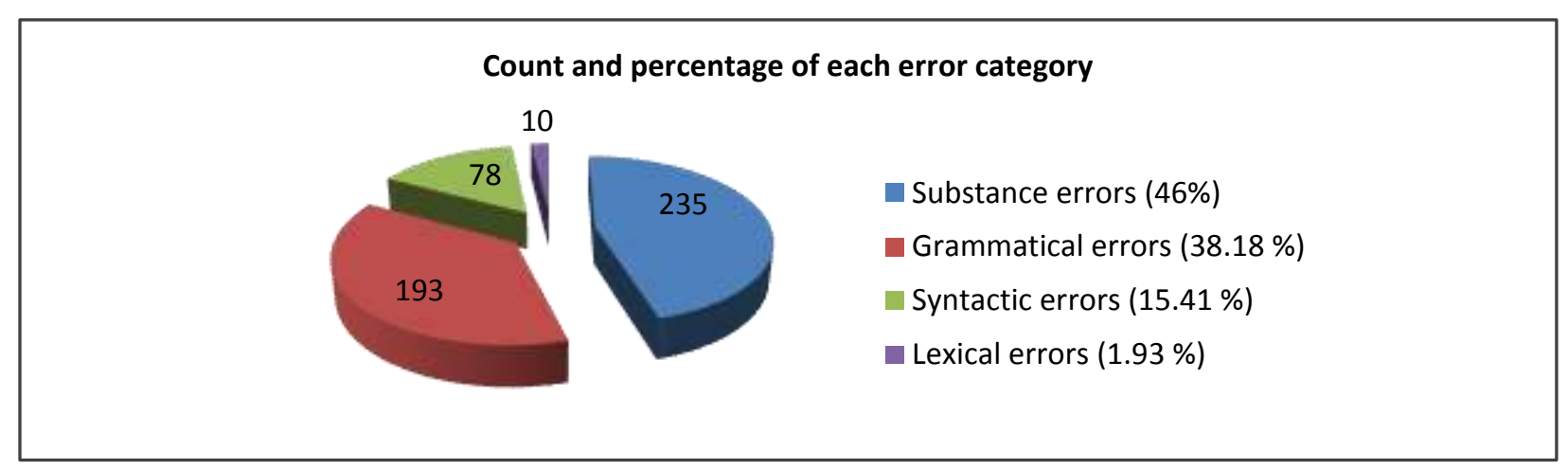

Figure 1. Percentage and count of errors in each error category

As indicated through statistical tools in the Figure 1, substance errors occurred most frequently with the count of 234 and percentage of $46 \%$. Grammatical errors with 193 and $38.18 \%$ of all errors was second most dominant errors followed by syntactic errors with 78 and $15.41 \%$ as the third most frequent errors. The least dominant error category was lexical errors with 10 accounting for $1.93 \%$. All detected errors were explained and solved in DA sessions.

\subsection{Pre-test Results of Descriptive Statistics and Statistical Analysis}

Descriptive statistics and t-tests were presented for both sections of the pre-test and post-test. In order to pave the way to reach any effect of DA after mediation, an independent samples t-test was run to evaluate the Zone of Actual Development (ZAD) of the learners in using correct linguistic features. So, testing the linguistic homogeneity of the groups at the outset of the study is the basic issue. The indication of the descriptive statistics and statistical analysis for control and experimental groups' scores on pre-test is seen in Table 2. 
Table 2. Independent Samples t-test of the control and the experimental groups' pre-tests

\begin{tabular}{|c|c|c|c|c|c|c|}
\hline Groups & $\mathrm{N}$ & Mean & Std. Deviation & $\mathrm{t}$ & $\mathrm{df}$ & Sig \\
\hline Control Pre-test & 20 & 41.4000 & 4.24760 & \multirow{2}{*}{-1.592} & \multirow{2}{*}{38} & \multirow{2}{*}{.120} \\
\hline Experimental Pre-test & 20 & 44.2500 & 6.78912 & & & \\
\hline
\end{tabular}

Table 2 shows the mean scores and Standard Deviation in pre-test for control group (M=41.40, SD=2.24) and experimental group $(\mathrm{M}=44.25, \mathrm{SD}=6.78)$. The mean score of two groups turned out not to be very different. However, an independent t-test made it clear that there is no significant difference between the two groups' performances on writing static pre-test as $\mathrm{t}(38)=-1.59, \mathrm{p} .120>0.05$. It means that all students share the same potency regarding their linguistic ability, especially the determined linguistic components.

\subsection{Result of Pre-test and Post-test Descriptive Statistics and Statistical Analysis}

The data obtained from the pre-test and post-test in experimental group were analyzed in order to verify whether there are any differences as the result of applying interventionist DA on this group. Therefore, descriptive statistics were presented in table 3 .

Table 3. Descriptive statistics for the pre-test and post-test of the experimental group

\begin{tabular}{lcccc}
\hline Groups & $\mathrm{N}$ & Mean & St. Deviation & Std. Error Mean \\
\hline Experiment Pre-test & 20 & 41.4000 & 4.2476 & .94979 \\
Experiment Post-test & 20 & 70.8500 & 11.44909 & 2.56009 \\
\hline
\end{tabular}

As presented in Table 3, the mean score of experimental group in post-test $(M=70.85, S D=11.44)$ is higher than that of in pre-test $(\mathrm{M}=41.40, \mathrm{SD}=4.24)$. So to see if this improved mean is statistically significant, a paired sample $\mathrm{t}$-test was run and the results were depicted in the Table 4.

Table 4. Paired-Samples T-test of the pre-test and post-test of the experimental group

\begin{tabular}{lllllll}
\hline Groups & $\mathrm{N}$ & Mean & Std. Deviation & $\mathrm{t}$ & $\mathrm{df}$ & $\mathrm{sig}$ \\
\hline $\begin{array}{l}\text { Experimental pre-test/ } \\
\text { post-test }\end{array}$ & 40 & -29.450 & 2.6749 & -11.01 & 19 & .000 \\
\hline
\end{tabular}

Table 4 indicates a significance value of 0.00 . This $\mathrm{p}$ value was below the significance level set for the study. It means that the post-test mean score of the experimental group $(\mathrm{M}=70.85, \mathrm{SD}=11.44)$ is significantly different from its pretest's mean score $(\mathrm{M}=41.40, \mathrm{SD}=4.24)$, as $t(19)=-11.01, \mathrm{p}=.000<.05$ (two-tailed). By doing so, it was specified that to what extent the experimental group benefited from the intervention approach which was presented through a Sandwich Format. Therefore, improvement in writing through an interventionist model of DA had a large effect on writing achievement of the experimental group bore proofs that DA with specific reference to linguistic components in writing was efficacious.

\subsection{Result of Post-test Descriptive Statistics and Statistical Analysis}

In an attempt to compare the results born from the writings in the post-tests of experimental group and control group, descriptive statistics and statistical analysis were conducted as indicated in Table 5. By doing so, it was specified that 
to what extent the performances of the DA-group who received intervention and scaffolding and non-DA group who was treated traditionally and without any mediation were different (Table 5).

Table 5. Independent Samples $t$-test of the control and the experimental groups' post-tests

\begin{tabular}{lcccccc}
\hline Groups & $\mathrm{N}$ & Mean & St. Deviation & $\mathrm{t}$ & $\mathrm{df}$ & Sig \\
\hline Control Post-test & 20 & 45.1000 & 3.30709 & & \\
& & & & & \\
& & & & & \\
Experimental Post-test & 20 & 70.8500 & 11.44909 & & & \\
\hline
\end{tabular}

Based on the results gained from post-test, the independent t-test in Table 5 indicates that there is a difference between the experimental mean scores $(M=70.85, S D=11.44)$ and control group mean scores $(M=45.10, S D=3.30)$ on the posttest of writing in the second semester of education. The results of the t-test notifies the difference between the two groups' performance is significant in favor of the experimental group as $t(38)=-9.66, \mathrm{p}=.000<0.05$. The results demonstrated that after controlling for the root quantitative ability and doing homogenizing process, the differences in experimental post-test scores got significantly different from control group. It also depicted that, unlike treatment group, control group with getting traditional teaching couldn't improve its scores and did not perform better. However, the DA group outperformed the Non-DA group on the post-test.

\section{Discussion}

As mentioned before, the primary objective of the present study was to probe the effect of DA on the pre-determined linguistic errors of Iranian EFL learners' writing. For this aim, the type and frequency of each error was detected from their scripts in advance. Further, this study was conducted to examine whether there are any differences between the performances of the learners who were applied interventionist DA and that of those who did not expose to this mediation. Considering the results obtained as the result of data analysis, the related outcomes would be discussed in terms of the research questions.

1. What are the types and frequencies of linguistic errors which EFL learners commit in their writing performances? In an attempt to answer the first question of the research, the compositions of the two groups of students were investigated and based on of Ellis (1985) model of error analysis, the errors were identified, classified into different types and then explained and quantified in number and percentage. As a result, a number of different linguistic errors were found in the learners compositions. The errors were detected and classified based on Hubbard's et al. (1996) model of linguistic errors classification namely grammatical, syntactic, substance, and lexical errors.

As shown in Figure 1, substance errors are the most dominant error with $46 \%$ and total of 235 frequencies, second most dominant errors are grammatical errors with $38.18 \%$ errors with frequency of 193 , followed by 78 syntactic errors with $15.41 \%$ of errors, and the least dominant errors are lexical errors with $1.93 \%$ errors and 10 errors. However, to facilitate the requirements of the first question, the error analysis in Table 1 indicates the type, count, percentage, and sample of each error type related to these four categories in a hierarchy of descending order. The sub-categories are (1) Capitalization errors with 100 frequency accounted for $19.37 \%$. 2) Spelling with 89 errors took $17.24 \%$ of all errors. 3) Preposition with 55 error accounted for 10.65\%. 4) Verb with 50 errors owned 9.68\%. 5) Punctuation with 46 and $9.91 \%$ of entire errors. 6) Grammatical agreement (sub-verb agreement) with 34 held 6.58\% of errors. 7) Article with 34 frequency occupied $6.58 \%$ of errors. 8) Noun with 25 errors accounted for 5.23\%. 9) Conjunction with 27 errors took 5.23\%. 10) Pronoun with 23 errors accounted for 4.45\%. 11) adjective-adverb agreement with 21 frequencies took $4.06 \%$ of whole errors. Word choice with 10 and $1.93 \%$ and word order with no error were the least dominated errors.

Among these errors, participants had greatest difficulty with capitalizing the beginning of sentences and proper nouns or the name of cities and countries. They made a lot of mistakes in this area so that in any writing there have been several mistakes of this type. Spelling was the second common error. Most of the learners made awkward errors on spelling words. They dropped some letters in a word so that its meaning was missing during reading. The third type 
of error was in part of prepositions. Learners were not able to use proper prepositions before nouns and after verbs. So this problem had them think a lot finding a suitable preposition for words in their compositions. Then lacking a proposition caused misunderstanding of exact meaning of the word. The forth common errors which they had were from using correct verb forms and order of tenses in the sentences. They were also very confused about using modal auxiliaries and were not aware of using simple verb after modal verbs. They sometimes missed using to be verbs as linking verb.

The inattention of using punctuation marks like period, comma, exclamation points, and quotations was fifth mistake in the learners writing. This lacking attention to using punctuation became the reader confused about where a sentence was ended and where the next sentence started. It was also difficult to recognize when the writer was asking a question. So the type of sentences was ambiguous to the reader. Grammatical agreement and articles stood in sixth place where learners were not aware of principles of the agreement in grammar. The common mistake was disagreement between subject and verb when using singular subject pronouns and verbs they sometimes didn't use singular verbs. There were also disagreement between singular indefinite pronouns like anyone, somebody, and verbs. It shows that they are not familiar with singular and plural pronouns and verbs rules. And articles 'the' or 'a/an' were often dropped before nouns. Or some students didn't use 'a' or 'an' after demonstratives.

Nouns and conjunctions were located in seventh position of learner's difficulty. After plural to be verbs they sometimes didn't use plural nouns. They were also unaware of proper articles or collective nouns and didn't use proper verbs. And using proper conjunction for conclusion and comparison and contrast were difficult for them. Using incorrect pronouns specially object pronouns instead of possessive pronouns were seen sometimes difficult. Leaving out subject pronouns also was seen in some sentences. The eighth and last common error was using adjective, adverb incorrectly as modifiers of nouns. Some of them were not familiar with irregular comparative adverb like 'good' and used 'goodly' instead of 'well' as an adverb in the sentences. Unfamiliarity with adverb forms, they sometimes used adverb in place of adjective. Using 'many' before uncountable nouns was wrong use of adverb of quantity in the student's compositions. Adjective and adverb disagreement with the word they modify is also the serious case among learners. In lexical category, the learners sought help from their native language to choose a word. They did not check the selected words in their dictionaries which resulted in producing improper words.

The result drawn from this part of study is in line with that of Napitupulu (2017) in which he explored errors in Indonesian students' writing in English based on the two error analyses models in this study. This study revealed that students committed $42.4 \%$ of grammatical errors, $26.7 \%$ of syntactic errors, $17.9 \%$ of substance errors, and $13 \%$ of lexical errors. In this category, unlike the present study, most errors went to the grammatical category. The findings also support those of Sermsook et al. (2017) who examined the language errors in a writing of English major students in a Thai university to find the sources of the errors. 104 pieces of writing written by 26 second-year English major students were gathered and analyzed. Results indicated that the most frequently committed errors were punctuation, articles, subject-verb agreement, spelling, capitalization, and fragment in order.

2. To what extent can the interventionist model of DA promote the EFL learners' writings and alleviate linguistic errors? In another attempt to address the second question of the study, the results gained from pre-test and post-test were compared. The gained scores of the treatment group who underwent the interventionist DA during a period between pre-test and post-test improved significantly. It was as the result of reducing errors in post-test as they dealt with their pre-test difficulties with linguistic features of written language through activating their ZPD with the help of a more expert mediator. This is the core feature of DA to reveal potential abilities of less expert learners through moments of guiding them with proper hints, leading questions, examples, peer assistance, and finally explicit explanations. However, the significant effect of Interventionist DA was depicted through the descriptive statistics and statistical analysis in the Tables 3 and 4.

The figures in these two tables indicated a significantly different mean value between the pre and post- test of experimental group. It means that the post-test mean score of the experimental group $(\mathrm{M}=70.85, \mathrm{SD}=11.44)$ is higher than that of in pre- test $(\mathrm{M}=41.40, \mathrm{SD}=4.24)$. This mean difference confirmed a quantitative proof on a positive change in cognitive awareness of the learners toward their potential ability to solve the problems beyond their abilities. This change was later proved and labeled as significant through conducting the paired t-test in the Table 4 as $t(4)=-15.83$, $\mathrm{p}=.000<.05$ (two-tailed). This significant difference reveals that the experimental group performed better on the posttest than in the pre-test as they encountered mediations to elevate their ZAD. So this increased mean is the sign of improvement after treatment sessions. As can be inferred from this analysis, the DA group was affected and promoted 
to a great extent by mediation and their linguistic skills in terms of those grammatical features were promoted in the post test.

This finding obtained from the present study is in line with those of other ones who resulted in the realization that dynamic interventions can promote EFL language learners by a great extent. For instance, Taheri and Dastjerdi (2016) investigated the impact of DA on EFL learners' picture-cued writing. They reported a DA approach can successfully improve EFL learners' writing ability. They also suggest that a DA approach to writing enables the teacher to more accurately evaluate learners' writing skill and after identifying the nature of their errors provide them with necessary support and as a result, improve their writing. This was what supports the present study's methodology in conducting DA mediations as marked by Sandwich Format of DA. In this format, the learners' problems are detected based on which the mediations are applied to solve them before the next performance.

This finding is also similar to that of Isavi (2012) who investigated effectiveness of DA on 15 pre-intermediate Iranian EFL learners' L2 writing performance using the regulatory scale offered by Aljaafreh and Lantolf (1994) to Iranian EFL learners' writing ability. This study reported that almost all participants had difficulties in their writing ability and were only able to perform better with mediator guidance. It also reported that a DA approach can successfully improve EFL learners' writing ability to a great extent. The results also support those of Parsi and Sanavi (2015) in which writing proficiency of 45 Iranian intermediate EFL learners was investigated. The final results of this study indicated that using DA tools influences writing ability of Iranian female adult EFL learners and promotes it greatly. It was also found that DA in EFL classes can uncover the weaknesses of the students and provide interventions when necessary.

3. Is there any significant difference between the writing performances of dynamic and non-dynamic learners in promoting their linguistic problems? To answer the third question of the study, the performances of both dynamic group and non-dynamic groups' mean scores were investigated in pre-test and post-test. At the outset of the study, both groups were pretested with the aim of gaining access to their ZAD, since it was necessary to prove that these two groups were of close writing proficiency and came to do the pre-test with the same linguistic ability in writing. This was very important to sense the later change or improvement after mediation. However, the descriptive analysis and statistical analysis in Table 2 showed that this necessity was met and the two groups performed the same on the pretest. The descriptive statistics and independent t-test in Table 2 shows the mean scores and standard deviation in pretest for control group ( $M=41.40, S D=2.24)$ and experimental group $(M=44.25, S D=6.78)$ was close and no significant difference between the two groups' performances on writing static pre-test was found, as $t(38)=-1.59$, p.120>0.05.

This performance in Poehner's (2005) point of view makes a baseline measure based on which the effectiveness of treatment will be achieved on the post-test performance. After mediation, both groups were post-tested and the extent of their differences was shown through descriptive statistics and statistical analysis (independent t-test) in Table 5. It was shown that the dynamic group who underwent mediational interventions performed better in the post-test comparing to non-dynamic group who received no mediation. As the results gained from post-test, the descriptive statistics indicate a significant difference between the dynamic mean scores as $(\mathrm{M}=70.85, \mathrm{SD}=11.44)$ and nondynamic mean scores $(M=45.10, \mathrm{SD}=3.30)$ on the writing post-test. The results of the independent t-test also marked that the difference between the two groups' performance is significant in favor of the dynamic group as $t(38)=-9.66$, $\mathrm{p}=.000<0.05$. Thus, the DA group in the post-test outperformed the non-DA group.

It also proved that there is a significant difference between writing performances of dynamic and non-dynamic groups in promoting their linguistic abilities at the end of study. The outcomes of this study indicated that almost all the learners in the research had problems in the writing and improved their writings by experiencing the mediation and assistance. The mediation provided for the individuals was various in each of them because the ZPD was different among them. Some of them overcame the problems after reviewing; some others by very explicit hints and explanations. Thus, this change in the performance of dynamic mediated groups puts in the practice the ideas of Sternberg, Torff, and Grigorenko (1998) and Haywood and Lidz (2007) who state those meditational strategies that are fit to the learners' ZPD are able to flourish new abilities with the help of mediators. This amount of obtained improvement and ideal learning as the result of applying DA on language skills proved the feasibility of this novel method of testing over psychometric way testing in the literature of applied linguistics.

The present study also supports the results of Alemi's (2015) study which investigated general English students' evaluation of their writing ability before and after taking a DA-based writing course. The findings were evidence of the consistent self-rating and teacher-scaffold DA provided general English students with insights into their writing 
ability which led to their more accurate assessment of their writing ability. The results suggested that DA could help Iranian EFL learners to get a better awareness of their criteria for writing evaluation. The results also suggested that a DA approach to writing enables the teacher to more accurately evaluate learners' writing skill and after identifying the nature of the error provide the learners with necessary support and improve their writing. In this study, the dynamic group after mediation outperformed the non-dynamic group in post-test.

The result of this study turned out to be in parallel with another one by Xiaoxiao and\&Yun (2010) who conducted a case study of DA in EFL process writing. The result obtained from this study represents two major objectives. 1) Learners' writing ability can be substantially and comprehensively improved; 2) Learners' motivation of writing can be markedly stimulated. However, they found DA can affect the whole process of writing. They also stressed the role of interaction between mediators and learners aided by language (dialogue) or other mediational tools (mediation). They reported that since the mediation is made in the ZPD of dynamic treated learners, remarkable progress is likely to occur in comparison to non-dynamic group. The general DA research literature includes studies on different language skills with different models of DA and their practicality in line with the current study has been proved in so many studies; Ableeva (2010) on listening, Poehner (2005) on speaking, and many other DA studies like those by Hidri (2014), Ajideh and Nourdad (2012), and Poehner and Lantolf (2005). They all called DA effective for language development and maturing mental cognition of learners.

\section{Conclusion}

As the questions of this study imply, the present research was to analyze the accuracy of the EFL learners' writings and apply interventionist DA as a psychological support to alleviate the detected errors. However, the findings of the qualitative content analysis of errors revealed that EFL learners have made a lot of mistakes in their compositions labeled as grammatical, syntactic, substance, and lexical errors. It was shown that substance errors were the most dominant error with $46 \%$ and total of 235 frequencies, second most dominant errors were grammatical errors with $38.18 \%$ errors with frequency of 193 , followed by 78 syntactic errors with $15.41 \%$ of errors, and the least dominant errors were lexical errors with $1.93 \%$ errors and 10 errors. Further, in order to implement the privileged role of error analysis in language learning and teaching promotion, dynamic mediations were adopted later to remove linguistic errors and promote writing accuracy among learners. In this regard, the results of statistical analysis showed that DA especially interventionist could affect EFL learners' knowledge of linguistic issues and promote their writing abilities to a great extent. It means that the dynamic learners' ZPDs in mediation sessions were properly activated through implicit and explicit interventions and their future knowledge was nurtured in the post-test phase. Outperformance of DA members over non-dynamic proved DA practicality in accomplishing the goals of learning especially over static assessment procedures.

It was also concluded that clinging DA approaches to error analysis procedures can bore systematic knowledge about dynamic testing administration, since mediation strategies are directed to the detected errors with prior preparations. This study, in spite of its tangible results, suffers from some limitations such as non-random sampling of the participants would be a case for the generalization of the results. Another limitation is that DA was applied on only linguistic errors of writing so other aspects require further research. Too, it is worth to conduct another study and try interactionist DA and then compare the findings with the current study. However, the results of this research can bore implications for test designers, material writers, syllabus makers, EFL teachers, and all who are involved in language teaching and learning to take into account the procedures of DA as a reflection on language testing and teaching to accomplish learning.

\section{References}

Abdolrezapour, P., Tavakoli, M., \& Ketabi, S. (2014). Qualitative analysis of mediational strategies in emotionalized dynamic assessment of L2 reading comprehension. International Journal of Research Studies in Language Learning, 3(1), 51-66. doi:10.5861/ijrs11.2013.506

Ableeva, R. (2008). The effects of dynamic assessment on L2 listening comprehension. In J. P. Lantolf \&, M. E. Poehner (Eds.), sociocultural theory and the Teaching of Second languages. (pp. 57-86). London, Equinox.

Ableeva, R. (2010). Dynamic assessment of listening comprehension in second language learning. Unpublished doctoral dissertation, The Pennsylvania State University, University Park, PA. $\underline{\text { https://etda.libraries.psu.edu/catalog/11063 }}$ 
Ajideh, P., \& Nourdad, N. (2012). The effect of dynamic assessment on EFL reading comprehension in different proficiency levels. Language Testing in Asia, 2(4), 101-122. doi: 10.1186/2229-0443-2-4-101

Aljaafreh, A., \& Lantolf, J. P. (1994). Negative feedback as regulation and second language learning in the zone of proximal development. Modern Language Journal, 78(4), 465-483. https://www.jstor.org/stable/328585

Alemi, M. (2015). The impact of dynamic assessment on Iranian EFL students' writing self-assessment. ELL, 9(1), 145-169. doi: $10.22132 /$ tel.2015.53735

Antón, M. (2009). Dynamic assessment of advanced second language learners. Foreign Language Annals, 42(3), 576598. doi: 10.1111/j.1944-9720.2009.01030.x.

Dunn, W. E., \& Lantolf, J. P. (1998). Vygotsky's zone of proximal development and Krashen's i+1: Incommensurable constructs; incommensurable theories. Language Learning, 48(3), 411-442. http://dx.doi.org/10.1111/0023$\underline{8333.00048}$

Ellis. R. (1994). The study of second language acquisition. Oxford: Oxford University Press.

Haywood, H. C., \& Lidz, C. (2007). Dynamic assessment in practice. Clinical and educational applications. New York: Cambridge University Press. doi: 10.1017/CBO9780511607516

Hidri, S. (2014). Comparison of the students' performance in dynamic vs. static listening comprehension tests among EFL learners. In article published in the Proceedings of the 19th TESOL Arabia Conference, From KG to College to Career. 51-59.

Hubbard, P., Jones, H., Thornton, B., \& Wheeler, R. (1996). A training course for TEFL. Oxford: Oxford University Press.

Isavi, E. (2012). The effect of dynamic assessment on Iranian L2 writing performance. Retrieved from http://eric.ed.gov/?id=ED530902

Kozulin, A, \& Garb, E. (2002). Dynamic assessment of EFL text comprehension of at-risk students. School Psychology International, 23(1), 112-127. https://doi.org/10.1177\%2F0143034302023001733

Lantolf, J. P., \& Poehner, M. E. (2004). Dynamic assessment in the language classroom (CALPER Professional Development Document CPDD-0411). University Park, PA: The Pennsylvania State University, Center for Advanced Language Proficiency Education and Research.

MacKey, A., \& Gass, S. (2006). Second language research: Methodology and design. Routledge.

MIAO, T., \& Lv, M. (2013). Dynamic assessment in ESL writing classroom. International Conference on Education Technology and Management Science, ICETMS, Beijing, Technology and Business University, 2013. China, Published by Atlantis Press.

Minick, N. (1987). Implications of Vygotsky's theories for dynamic assessment. In C. Lidz (Ed.), Dynamic assessment: An interactive approach to evaluating learning potential (pp. 116-140). New York: The Guilford Press. https://psycnet.apa.org/record/1987-98593-004

Napitupulu, S. (2017). Analyzing linguistic errors in writing an English letter: A case study of Indonesian undergraduate students, International Journal of Language and Linguistics, 5(3), 71-77.doi: 10.11648/j.ijl1.20170503.12

Parsi, P. P., \& Sanavi, R. V. (2015). The effects of dynamic assessment on improving writing ability of intermediate EFL learners. International Journal of Language Learning and Applied Linguistics World, 8(2), 73-88.

Poehner, M. E. (2005). Dynamic assessment of oral proficiency among advanced L2 learners of French (Unpublished doctoral dissertation). The Pennsylvania State University, University Park, PA. https://etda.libraries.psu.edu/catalog/6627

Poehner, M. E., \& Lantolf, J. P., (2004). Dynamic assessment of L2 development: Bringing the past into future. Journal of Applied Linguistics, 1(1), 49-72. https://pennstate.pure.elsevier.com 
Poehner, M. E., \& Lantolf, J. P. (2005). Dynamic assessment in the language classroom. Language Teaching Research, 9(3), 233-265. https://doi.org/10.1191\%2F13621688051r1660a

Poehner, M. E., \& Lantolf. J. P. (2013). Bringing the ZPD into the equation: Capturing L2 development during computerized dynamic assessment (C-DA) Language Teaching Research, 17(3), 323-342. https://journals.sagepub.com/doi/10.1177/1362168813482935

Sermsook, K., Liamnimitr, J., \& Pochakorn, R. (2017). An analysis of errors in written English sentences: A case study of Thai EFL students. English Language Teaching, 10(3), 101-110. doi: 10.5539/elt.v10n3p101 URL: http://dx.doi.org/10.5539/elt.v10n3p101

Shepard, L. (2000). The role of assessment in a learning culture. Educational Researcher, 29(7), 4-14. https://eric.ed.gov/?id=EJ615905

Shrestha, P. (2011). Dynamic assessment of academic writing for business studies. Ph.D. Doctoral Thesis, The Open University, Milton Keynes. http//:www.isfla.org/Systemics/Print/Theses/Thesis-FINAL-Prithvi-Shrestha.pdf

Sternberg, R. J., \& Grigorenko, E. L. (2002). Dynamic testing. The nature and measurement of learning potential. Cambridge: Cambridge University Press. https://psycnet.apa.org/record/2002-01422-000

Sternberg, R. J., Torff, B., \& Grigorenko, E. L. (1998). Teaching triarchically improves school achievement. Journal of Educational Psychology, 90(3), 374-384. http://dx.doi.org/10.1037/0022-0663.90.3.374

Taheri, R., \& Dastgerdi, V. H. (2016). Impact of dynamic assessment on Iranian EFL learners' picture-cued writing. International Journal of Foreign Language Teaching and research, 4(13), $129-144$. $\underline{\text { http//:jfl.iaun.ac.ir/article 561178.html }}$

Teo, k. (2012). Effects of dynamic assessment on College EFL learners' reading skills. The Journal of Asia TEFL, 9(1), 57-94. www.asiatefl.org/main/download_pdf.php?i=104\&c=1419300554

Tzuriel, D. (2000). Dynamic assessment of young children: Educational and intervention perspectives. Educational Psychology Review, 12(4), 385-435. https://link.springer.com/article/10.1023/A:1009032414088

Vygotsky, L. S. (1978). Interaction between Learning and Development. In M. Cole, V. John-Steiner, S. Scribner, \& E. Souberman (Eds.), Mind and society: The development of higher psychological processes (pp. 79-91). Cambridge, MA: Harvard University Press.

Vygotsky, L. S. (1986). Thought and language. Cambridge: The MIT Press.

Wang, P. (2015). The effect of dynamic assessment on the listening skills of lower-intermediate EFL learners in Chinese technical college: A pilot study. Journal of Language Teaching and research, 6(6), 1269-1279. doi: http://dx.doi.org/10.17507/jltr.0606.14

Xiaoxiao, L., \& Yan, L. (2010). A case study of dynamic assessment in EFL process writing. Chinese Journal of Applied Linguistics, 33(1), 24-40. www.celea.org.cn/teic/89/10042202.pdf 